Article

\title{
Biological Activities and Chemical Composition of Methanolic Extracts of Selected Autochthonous Microalgae Strains from the Red Sea
}

\author{
Hugo Pereira ${ }^{1, \dagger}$, Luísa Custódio ${ }^{1, \dagger}$, Maria João Rodrigues ${ }^{\mathbf{1}}$, Carolina Bruno de Sousa ${ }^{\mathbf{1}}$, \\ Marta Oliveira ${ }^{1}$, Luísa Barreira ${ }^{1}$, Nuno da Rosa Neng ${ }^{2}$, José Manuel Florêncio Nogueira ${ }^{2}$, \\ Salman A. Alrokayan ${ }^{3}$, Fouzi Mouffouk ${ }^{3,4}$, Khalid M. Abu-Salah ${ }^{3,5, *}$, Radhouan Ben-Hamadou 6 \\ and João Varela ${ }^{1, *}$
}

1 Centre of Marine Sciences, University of Algarve, Faro 8005-139, Portugal;

E-Mails: hgpereira@ualg.pt (H.P.); 1custodio@ualg.pt (L.C.); mary_p@sapo.pt (M.J.R.); carolbrunos@yahoo.com (C.B.S.); mmfoliveira@live.com.pt (M.O.); lbarreir@ualg.pt (L.B.)

Department of Chemistry and Biochemistry and Center of Chemistry and Biochemistry, Faculty of Sciences, University of Lisbon, Campo Grande, Ed. C8, Lisbon 1749-016, Portugal; E-Mails: nunoneng@gmail.com (N.R.N.); jmnogueira@fc.ul.pt (J.M.F.N.)

3 King Abdullah Institute for Nanotechnology, King Saud University, Riyadh 11451, Saudi Arabia; E-Mails: salrokayan@ksu.edu.sa (S.A.A.); fmouffouk@gmail.com (F.M.)

4 Department of Chemistry, Faculty of Science, Kuwait University, Safat 13060, Kuwait

5 King Abdullah International Medical Research Center, King Abdulaziz Medical City, Riyadh 11426, Saudi Arabia

6 Department of Biological and Environmental Sciences, College of Arts and Sciences, Qatar University, Doha, Qatar; E-Mail: benhamadou@qu.edu.qa

$\dagger$ These authors contributed equally to this work.

* Authors to whom correspondence should be addressed;

E-Mails: k_abusalah@hotmail.com (K.M.A.-S.); jvarela@ualg.pt (J.V.);

Tel.: +966-1-469-5433 (K.M.A.-S.); +351-28980-0051 (J.V.);

Fax: +966-1-467-7317 (K.M.A.-S.); +351-28980-0051 (J.V.).

Academic Editor: Anake Kijjoa

Received: 16 March 2015 / Accepted: 26 May 2015 / Published: 3 June 2015

Abstract: Four lipid-rich microalgal species from the Red Sea belonging to three different genera (Nannochloris, Picochlorum and Desmochloris), previously isolated as novel biodiesel feedstocks, were bioprospected for high-value, bioactive molecules. Methanol extracts 
were thus prepared from freeze-dried biomass and screened for different biological activities. Nannochloris sp. SBL1 and Desmochloris sp. SBL3 had the highest radical scavenging activity against 1,1-diphenyl-2-picrylhydrazyl, and the best copper and iron chelating activities. All species had potent butyrylcholinesterase inhibitory activity $(>50 \%)$ and mildly inhibited tyrosinase. Picochlorum sp. SBL2 and Nannochloris sp. SBL4 extracts significantly reduced the viability of tumoral (HepG2 and HeLa) cells with lower toxicity against the non-tumoral murine stromal (S17) cells. Nannochloris sp. SBL1 significantly reduced the viability of Leishmania infantum down to $62 \%(250 \mu \mathrm{g} / \mathrm{mL})$. Picochlorum sp. SBL2 had the highest total phenolic content, the major phenolic compounds identified being salicylic, coumaric and gallic acids. Neoxanthin, violaxanthin, zeaxanthin, lutein and $\beta$-carotene were identified in the extracts of all strains, while canthaxanthin was only identified in Picochlorum sp. SBL2. Taken together, these results strongly suggest that the microalgae included in this work could be used as sources of added-value products that could be used to upgrade the final biomass value.

Keywords: antioxidants; bioprospection; BuChE inhibitors; carotenoids; microalgae; oxidative stress; phenolics

\section{Introduction}

Microalgae are found in almost all environments (both aquatic and terrestrial), and it has been suggested that their number may be as high as 50,000 species [1]. This biodiversity and distribution has provided a wide array of biochemicals, some of them enabling microalgae to thrive in niche and extreme habitats [2], while displaying several important bioactivities. Microalgae are thus considered as a promising feedstock for the extraction of secondary metabolites for successful commercial applications (e.g., Martek and BASF/Betatene Ltd.). Several secondary metabolites identified in microalgae have high commercial value and include carotenoids (e.g., astaxanthin, lutein and $\beta$-carotene) and long chain polyunsaturated fatty acids (PUFA), such as eicosapentaenoic (EPA) and docosahexaenoic (DHA) acids [3]. The main advantage of microalgae as sources of novel bioactive molecules is their vast biodiversity. Moreover, microalgae are usually fast-growing unicellular organisms that can be cultivated in large-scale systems (e.g., open ponds and photobioreactors), allowing a continuous supply of large quantities of biomass and of desired molecules [4]. Lastly, bulk microalgal biomass or fractions thereof can be used in nutraceutical applications, simultaneously upgrading the total biomass value and limiting the costs associated with the isolation of specific compounds [5].

The interest in microalgae as novel sources of high-value chemicals and/or other products has recently increased due to the efforts of using these organisms as renewable biofuel feedstock [3]. In fact, microalgal biomass is currently considered as one of the most promising feedstocks for the large-scale production of biofuels [6]. However, it has been proposed that commercial biofuel production can only be economically feasible if high-value components of the algal biomass are 
exploited as co-products, together with the use of the triacylglycerols for the production of biodiesel in a biorefinery setting [6-8].

In a previous work, Pereira et al. [9] identified and isolated four microalgal strains from environmental water samples collected off Al-Lith in the Red Sea (west coast of Saudi Arabia) by fluorescent-activated cell sorting (FACS). The selected isolates were identified by ribosomal DNA sequencing and classified as chlorophytes belonging to three different genera, namely Picochlorum, Nannochloris and Desmochloris. All strains had inner cell lipid contents ranging from $20 \%$ to $25 \%$ of the biomass dry weight (DW), with fatty acid profiles appropriate for biodiesel production [9]. In this work, a bioprospection for commercially-relevant metabolites with the biomass of the aforementioned microalgae was performed. These include pigments and secondary metabolites with valuable biological activities (e.g., free radical scavenging, metal chelating and cholinesterase inhibitory activities, as well as cytotoxicity towards human tumoral cell lines and Leishmania parasites), which can have a wide application in the food, feed and pharmaceutical industries. To the authors' knowledge, the biological activities here described have never been reported in Nannochloris, Picochlorum and Desmochloris microalgae.

\section{Results and Discussion}

\subsection{Antioxidant Activity}

Free radicals, more specifically reactive oxygen species (ROS) and reactive nitrogen species (RNS), have both beneficial and deleterious roles in the human body. When present at very low concentrations, they may act as a second messenger in some of the signal transduction pathways [10]. However, when the production of ROS and/or RNS overcomes the antioxidant defenses of the organism, oxidative stress may occur, which is implicated in the pathogenesis of several chronic diseases. The use of antioxidants can thus prevent and/or reduce the severity of those oxidative stress-related diseases, such as cancer, diabetes, cardiovascular disorders and neurological ailments [11-15]. ROS are constantly produced in the brain by excitatory amino acids and neurotransmitters and can lead to oxidative stress with the associated damage to glial and neuronal cells [16]. In this context, the use of antioxidants to prevent cerebral oxidative stress and neuronal loss has gained increasing importance due to their capacity to neutralize free radicals $[13,16]$.

In this study, methanol extracts were prepared from dried biomass of four microalgae strains and evaluated for radical scavenging activity (RSA) on the 1,1-diphenyl-2-picrylhydrazyl (DPPH) radical. All species had moderate or high RSA, and the highest values were observed in Nannochloris sp. SBL1 and Desmochloris sp. SBL3 with RSA values of $60 \%$ and $61 \%$, respectively, at a concentration of $10 \mathrm{mg} / \mathrm{mL}$ (Figure 1). Butylated hydroxytoluene (BHT; positive control) had an RSA of $88 \%$ at a concentration of $1 \mathrm{mg} / \mathrm{mL}$. These results suggest that those species may be sources of compounds with anti-radical properties. Generally, extracts had a higher ability to chelate $\mathrm{Fe}^{2+}$ than $\mathrm{Cu}^{2+}$ (Figure 1), similar to previous findings in other microalgae [17], such as N. oculata. Regarding iron chelation, the highest activity was obtained with Desmochloris sp. SBL3 (81\%) followed by Nannochloris sp. SBL1 $(70 \%)$ at a concentration of $10 \mathrm{mg} / \mathrm{mL}$ (Figure 1). Those species were also able to chelate copper, with values of $61 \%$ and $45 \%$ at a concentration of $10 \mathrm{mg} / \mathrm{mL}$ (Figure 1). Iron may promote the deposition of 
$\beta$-amyloid plaques, which is one of the hallmarks of the progression of Alzheimer's disease (AD). Moreover, the accumulation of both $\mathrm{Fe}^{2+}$ and $\mathrm{Cu}^{2+}$ increase the production of ROS through the promotion of the Haber-Weiss/Fenton reaction, which may be responsible for the increase in global oxidative stress parameters observed in $\mathrm{AD}$ patients $[15,18]$. Thus, the use of $\mathrm{Fe}^{2+}$ and $\mathrm{Cu}^{2+}$ chelators is a valuable strategy in the management of oxidative stress-related neurological disorders [15]. The importance of novel metal chelators is highlighted by the side effects caused by current chelation therapies, which may cause allergic reactions, as well as ophthalmological, auditory and bone toxicity, most probably caused by their lack of specificity or "over-chelation" [19]. Our results suggest that the extract showing higher selectivity for iron corresponds to that of Picochlorum sp. SBL2. Lower selectivity between iron and copper chelation is apparent for the Desmochloris sp. SBL3 (Figure 1). Interestingly, a recent report on metal chelators suggests that compounds with lower sequestration capacity, but higher specificity may be more promising candidates for novel therapeutic leads. Selective chelators with lower binding activity may be able not only to remove the metal from disease-causing "sinks", but also to more readily release the metal in other cellular compartments where they are needed [20]. Such mechanism could be a way forward to reduce the adverse effects of known metal chelators.
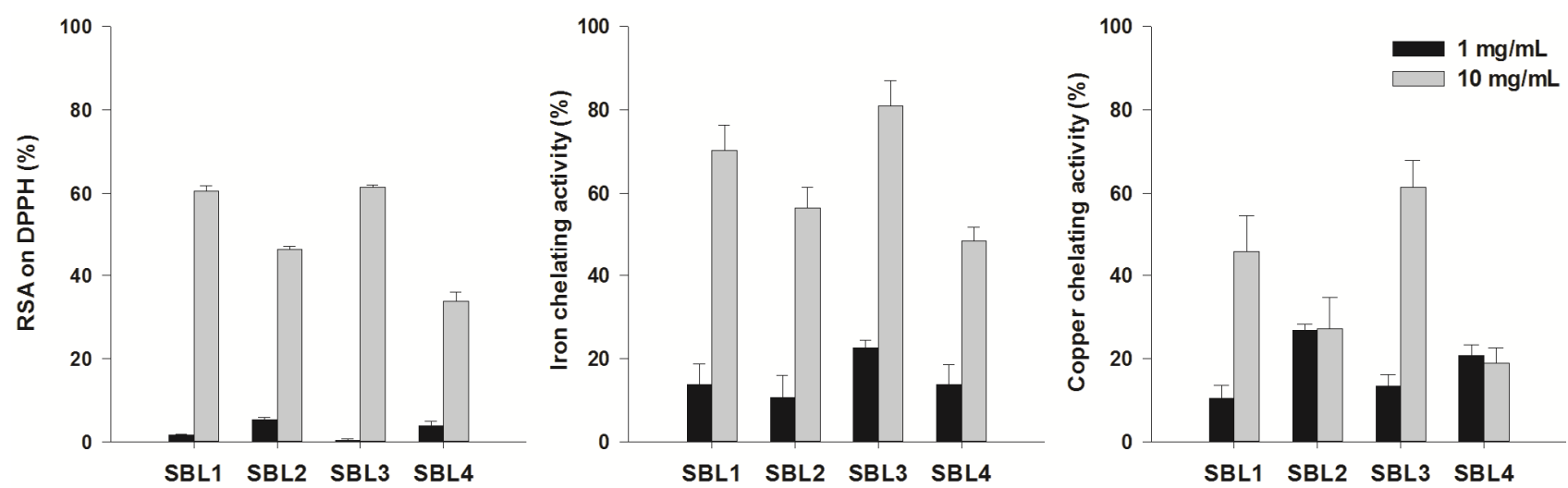

Figure 1. Radical scavenging activity (RSA) on the free radical 1,1-diphenyl-2-picrylhydrazyl (DPPH) and iron and copper chelating activities of methanol extracts of four strains belonging to the Nannochloris (SBL1 and SBL4), Picochlorum (SBL2) and Desmochloris (SBL3) genera. Solid and error bars represent the average and standard deviation values, respectively $(n=6)$. Butylated hydroxytoluene (BHT; positive control) had an RSA of $88 \%$ at $1 \mathrm{mg} / \mathrm{mL}$. Ethylenediamine tetraacetic acid (EDTA; positive control) had a metal chelating activity of $76 \%$ (copper) and $96 \%$ (iron) at a concentration of $1 \mathrm{mg} / \mathrm{mL}$.

\subsection{Acetylcholinesterase, Butyrylcholinesterase and Tyrosinase Inhibitory Activity}

$\mathrm{AD}$ is characterized by the loss of cholinergic neurons in the forebrain and by a progressive decline in the levels of acetylcholine (ACh) due to hydrolytic reactions catalyzed by acetylcholinesterase $(\mathrm{AChE})$ and butyrylcholinesterase $(\mathrm{BuChE})$ [21]. Thus, research has focused on the identification of cholinergic inhibitors (ChEIs) able to increase the activity of surviving cholinergic neurons in patients with AD. This is the case of the drugs currently used as therapeutics in AD, specifically 
galantamine/Razadyne ${ }^{\circledR}$, Janssen, an AChE inhibitor, and rivastigmine/Exelon ${ }^{\circledR}$, Novartis, a compound with a dual effect on $\mathrm{AChE}$ and BuChE.

In this work, the inhibitory activity (\%) towards $\mathrm{AChE}$ and $\mathrm{BuChE}$ was classified as potent ( $>50 \%)$, moderate $(30 \%-50 \%)$, low $(<30 \%)$ or nil $(<5 \%)$ [22]. According to this classification, extracts had low and nil inhibitory potential on $\mathrm{AChE}$, but displayed potent activity towards BuChE. The opposite was observed in other microalgae, namely Botryococcus braunii and Nannochloropsis oculata [23], where a high AChE inhibition was observed, but no relevant BuChE inhibitory activity was detected. The highest BuChE inhibitory effect was obtained with Picochlorum sp. SBL2 at the highest concentration tested $(10 \mathrm{mg} / \mathrm{mL}, 69.3 \%$ of inhibition; Table 1$)$. Although some of the functions of BuChE are common to AChE (i.e., to catalyze ACh hydrolysis), the exact role of the former enzyme is still unclear [24]. However, there is evidence that some cholinergic neurons contain BuChE instead of AChE [25], and thus, the increase of the cholinergic function through the inhibition of $\mathrm{BuChE}$ may be of clinical value. Our results suggest that the microalgae under study contain compounds that can inhibit BuChE, which could be used in combination with AChE inhibitors (Table 1) [26]. Indeed, clinical studies with the dual ChEI, rivastigmine, support a role for the central inhibition of $\mathrm{BuChE}$ in addition to AChE in AD therapy [27]. Noteworthy is the fact that $\mathrm{BuChE}$ inhibition was evident with the lowest concentration tested and that increasing a concentration applied was not followed by an increase of the inhibitory activity. A possible explanation for this may be related to the balance between inhibitors and activators of BuChE, which can be present in crude extracts [28]. Hence, upon increasing a concentration of the extracts, both types of compounds will equally increase, resulting in an unaltered inhibitory effect.

The extracts were also evaluated for their inhibitory potential against tyrosinase (TYRO), a multifunctional copper-containing enzyme that plays a pivotal role in melanin biosynthesis [29]. TYRO is also involved in neuromelanin formation in the human brain and, due to its oxidase activity, can potentially accelerate the induction of catecholamine quinone derivatives, contributing to dopamine neurotoxicity and to neurodegeneration associated with Parkinson's disease (PD) [29]. In this sense, TYRO inhibitors have become an attractive target for the treatment of PD. Except for Nannochloris sp. SBL4, which imposed no inhibitory effect on TYRO, all strains had moderate activity on this enzyme, at $10 \mathrm{mg} / \mathrm{mL}$ (Table 1), which indicates the presence of compounds in those species with potential interest for PD therapeutics [29].

Table 1. Acetylcholinesterase (AChE), butyrylcholinesterase (BuChE) and tyrosinase (TYRO) inhibitory activity (\%) of methanol extracts of four strains belonging to the Nannochloris (SBL1 and SBL4), Picochlorum (SBL2) and Desmochloris (SBL3) genera. Values are represented as the mean and standard deviation $(n=6)$.

\begin{tabular}{ccccccc}
\hline & \multicolumn{2}{c}{ AChE } & \multicolumn{2}{c}{ BuChE } & \multicolumn{2}{c}{ TYRO } \\
\hline Species/Standard & $\mathbf{1 ~} \mathbf{~ m g} / \mathbf{m L}$ & $\mathbf{1 0} \mathbf{~} \mathbf{~ g} / \mathbf{m L}$ & $\mathbf{1} \mathbf{~} \mathbf{~ g} \mathbf{m L}$ & $\mathbf{1 0} \mathbf{~ m g} / \mathbf{m L}$ & $\mathbf{1 ~} \mathbf{~ m g} \mathbf{m L}$ & $\mathbf{1 0} \mathbf{~ m g} / \mathbf{m L}$ \\
\hline SBL1 & na & $17.1 \pm 5.7$ & $52.0 \pm 8.4$ & $58.0 \pm 7.4$ & $22.7 \pm 4.6$ & $44.8 \pm 5.1$ \\
SBL2 & na & $21.2 \pm 8.1$ & $66.1 \pm 3.4$ & $69.3 \pm 2.5$ & $32.6 \pm 7.3$ & $39.5 \pm 5.4$ \\
SBL3 & na & na & $55.2 \pm 6.5$ & $60.4 \pm 5.2$ & $15.0 \pm 5.2$ & $40.1 \pm 3.5$ \\
SBL4 & na & na & $59.0 \pm 8.2$ & $41.2 \pm 12.0$ & $10.6 \pm 4.1$ & na \\
Galantamine * & $93.2 \pm 0.5$ & nt & $80.3 \pm 0.7$ & nt & - & - \\
Arbutin * & - & - & - & - & $78.3 \pm 0.1$ & nt \\
\hline
\end{tabular}

* Positive control; nt, not tested; na, no activity. 


\subsection{In Vitro Cytotoxic Activity}

According to the World Health Organization (WHO), cancer is responsible for about 13\% ( 7.6 million) of fatalities worldwide, being the second most common cause of death from disease after myocardial infarction. The current available antitumoral drugs generally display undesirable effects, making the search for more effective and safer drugs necessary. The algal extracts under study were thus tested against two human tumoral cell lines, namely: HepG2 (hepatocellular carcinoma) and HeLa (cervical carcinoma). Samples were applied for $72 \mathrm{~h}$ at a concentration of $125 \mu \mathrm{g} / \mathrm{mL}$, and cell viability was assessed by the 3-(4,5-dimethylthiazol-2-yl)-2,5-diphenyltetrazolium bromide (MTT) colorimetric assay [30]. To evaluate selectivity, samples were applied to a murine non-tumoral cell line (S17, stromal cells). None of the extracts were cytotoxic to non-tumoral cells and displayed different degrees of toxicity towards tumoral cell lines (Figure 2). Nannochloris sp. SBL1 and Desmochloris sp. SBL3 did not reduce significantly the viability of any of the cell lines tested, suggesting a nontoxic nature for the compounds present in the extract of those species. Extracts from Picochlorum sp. SBL2 and Nannochloris sp. SBL4 significantly reduced the viability of both HepG2 and HeLa cells, with lower toxicity against non-tumoral S17 cells. However, Nannochloris sp. SBL4 extracts showed the highest selectivity index (SI), suggesting that this strain contains molecules with interesting antitumoral properties that may act selectively on cancer cells. Although microalgae have long been recognized as sources of important biomolecules with potential medical uses [31], there have been few reports on their cytotoxicity against human tumoral cells $[32,33]$.

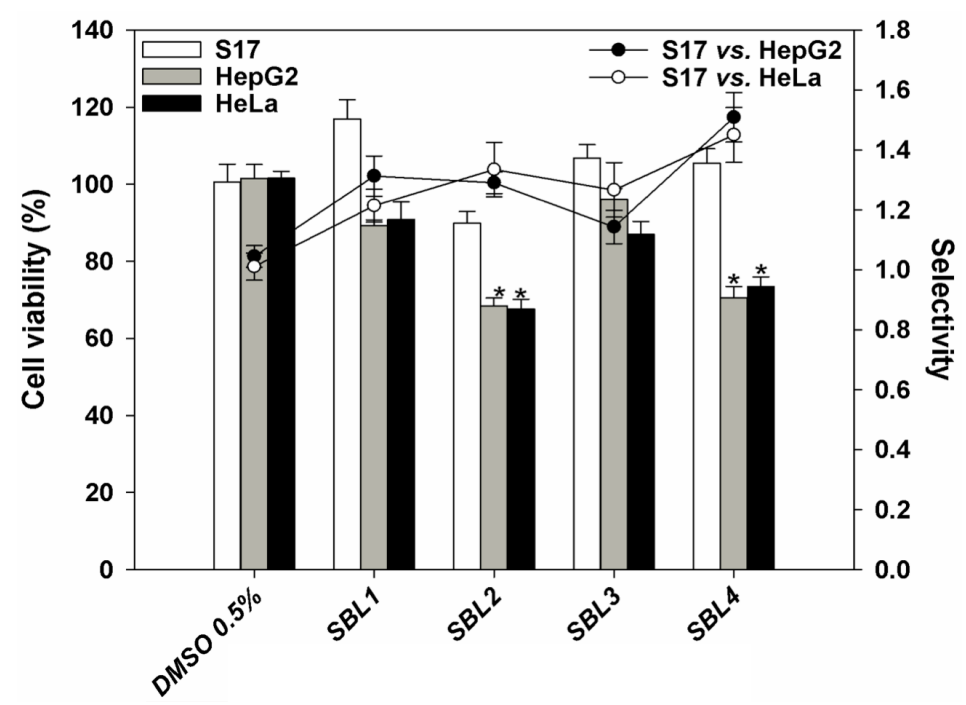

Figure 2. Effect of the application of methanol extracts of four strains belonging to the Nannochloris (SBL1 and SBL4), Picochlorum (SBL2) and Desmochloris (SBL3) genera, applied at a concentration of $125 \mu \mathrm{g} / \mathrm{mL}$ for $72 \mathrm{~h}$, on the viability of human hepatocarcinoma (HepG2), cervical carcinoma (HeLa) and non-tumoral murine stromal (S17) cell lines, in comparison to a control without extract (DMSO, 0.5\%, v/v). Bars and lines correspond, respectively, to cell viability and selectivity. * Significant differences $(p<0.001)$ compared with the control $(n=6)$. Half maximal inhibitory concentrations for etoposide used as a positive control were 1.9, 4.2 and $10 \mu \mathrm{g} / \mathrm{mL}$ for HepG2, HeLa and S17 cells, respectively. 


\subsection{In Vitro Antileishmanial Activity}

Leishmania infantum is the causative agent of canine leishmaniasis and both cutaneous and visceral forms of human leishmaniasis in the Mediterranean region [34]. The disease is endemic in all 22 countries of this area, where it is considered as a serious public health and veterinary problems [35]. In the Iberian Peninsula, the infection by L. infantum in humans is mainly related to immunosuppressive diseases, especially HIV co-infection [36,37]. Cases that are not the result of co-infection occur mostly in children. At present, there are no effective human or canine vaccines, and chemotherapy is the only means of controlling leishmaniases. However, currently applied drugs have high costs, depend on long-term administration and display high toxicity and reduced efficacy due to increasing parasite resistance $[38,39]$. Hence, the search for novel, safe, non-toxic and cost-effective drugs that can be used alone or in combination therapies to antileishmanial therapy and/or immunoprophylaxis is urgent [38-41].

In this work, samples were applied to $L$. infantum promastigotes at a concentration of $250 \mu \mathrm{g} / \mathrm{mL}$ for $48 \mathrm{~h}$, and cell viability was determined by the MTT assay (Figure 3). Nannochloris sp. SBL1 was able to significantly reduce promastigotes viability down to $62 \%$, as compared with untreated cells. Parasites treated with amphotericin B as the standard drug exhibited a viability of $47 \%$ at a concentration of $0.23 \mu \mathrm{g} / \mathrm{mL}$ (Figure 3). Marine organisms are recognized as a source of novel products and as a promising alternative to antileishmanial therapy and control $[39,42]$. However, there were no reports until now on the antileishmanial potential of microalgae. Assays are now being performed to ascertain the in vitro toxicity of this strain on intracellular amastigotes of $L$. infantum.

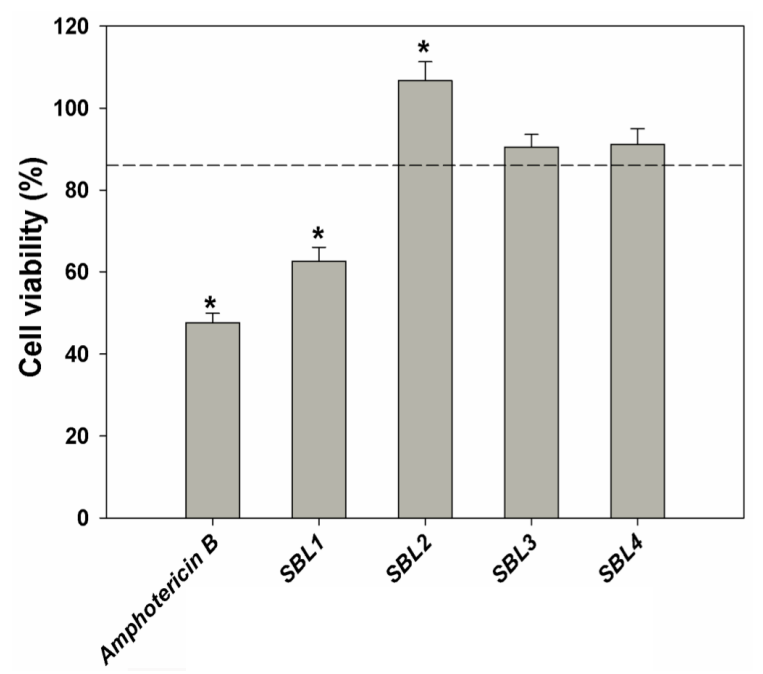

Figure 3. Effect of the application of methanol extracts of four strains belonging to the Nannochloris (SBL1 and SBL4), Picochlorum (SBL2) and Desmochloris (SBL3) genera at a concentration of $250 \mu \mathrm{g} / \mathrm{mL}$ for $48 \mathrm{~h}$ on the viability of Leishmania infantum promastigotes expressed as percentage (\%), in comparison to a control (DMSO, 0.5\%, v/v). Amphotericin B was used as the positive control. * Significant differences $(p<0.01)$ compared with the control (promastigotes treated with 0.5\% DMSO, dashed line; $n=6$ ). 


\subsection{Extraction Yield and Phytochemical Analysis}

The polarity and the nature of the solvents used in the extraction process define the extraction yield and the composition of the obtained extracts and, thus, their biological activity [43]. In this work, the dried biomass was extracted with methanol. Since it is known that this solvent has affinity for a broad diversity of bioactive compounds, namely phenolic compounds [44] and carotenoids, this approach already allowed the extraction of bioactive compounds from different species of microalgae [17]. The extraction yields were as follows: Nannochloris sp. SBL1, 29.9\%; Picochlorum sp. SBL2, 32.2\%; Desmochloris sp. SBL3, 33.9\%; and Nannochloris sp. SBL4, 40.7\%.

In spite of being considered as important sources of bioactive compounds, data on the phenolic content of microalgae is scarce [17,23,31-33,45,46], and to the best of our knowledge, there are no reports on the phenolic composition of Nannochloris, Picochlorum and Desmochloris microalgae. The accurate quantification of different phenolic structural groups remains difficult [47]. Spectrophotometric (colorimetric) techniques are widely used and are convenient when dealing with several samples of unknown composition [48]. The highest total phenolic content (TPC) was obtained in Picochlorum sp. SBL2 (114 mg gallic acid equivalents (GAE)/g DW), followed by Nannochloris sp. SBL4 (83.3 mg GAE/g DW) and Desmochloris sp. SBL3 (59.3 mg GAE/g DW). Those values are higher than those reported for methanol extracts of other species of microalgae, namely Tetraselmis chuii, Nannochloropsis oculata, Chlorella minutissima and Rhodomonas salina [17]. Only Nannochloris sp. SBL1 had a low content of phenolic compounds (5.8 mg GAE/g DW). Samples were further analyzed by reverse-phase HPLC, and three phenolic acids (gallic, coumaric and salicylic acids) were identified in Nannochloris, Picochlorum and Desmochloris microalgae samples (Table 2). The phenolic composition varied as a function of the strain analyzed, and Picochlorum sp. SBL2 had the highest sum of phenolic compounds $(1.1 \mathrm{mg} / \mathrm{g}$ extract, DW), followed by Nannochloris sp. SBL4 (0.21 mg/g extract, DW), Nannochloris sp. SBL1 (0.12 mg/g extract, DW) and Desmochloris sp. SBL3 (0.07 mg/g extract, DW). Salicylic acid was the main phenolic detected in Picochlorum sp. $(0.64 \mathrm{mg} / \mathrm{g}$ extract, DW) and at a lower level in Nannochloris sp. SBL4 (0.14 mg/g extract, DW). Coumaric acid was the only phenolic acid common to all strains and was detected in similar concentrations in Nannochloris (0.06 mg/g extract, DW) and Desmochloris strains (0.07 mg/g extract, DW).

Biophenolics are considered to be the most common secondary metabolites in photosynthetic organisms. These compounds are potent antioxidants due to their capacity to scavenge singlet oxygen and free radicals by donating hydrogen from the phenolic hydroxyl groups. This results in a stable end product that does not initiate or propagate lipid oxidation [49]. Such antioxidant ability confers phenolics an important role in the prevention of oxidative stress-related diseases, such as cancer and neurological disorders. However, the phenolic content of microalgae is lower than the levels reported for terrestrial plants [50]. One must keep in mind that, similarly to what was observed for other bioactive molecules, such as carotenoids, the phenolic levels in algal biomass can be increased through the modification of the growing conditions [51,52].

Microalgae are known producers of different carotenoids displaying potent antioxidant and anti-carcinogenic activities [53]. Therefore, the carotenoid composition of all extracts was determined by HPLC and is shown in Table 2. Neoxanthin $(0.02-1.45 \mathrm{mg} / \mathrm{g}$ extract DW), violaxanthin (0.05-0.44 mg/g extract DW), lutein $(0.19-1.29 \mathrm{mg} / \mathrm{g}$ extract DW), zeaxanthin $(0.10-0.54 \mathrm{mg} / \mathrm{g}$ 
extract DW) and $\beta$-carotene $(0.52-1.19 \mathrm{mg} / \mathrm{g}$ extract DW) were detected in all strains. Canthaxanthin was only detected in Picochlorum sp. SBL2 (1.15 mg/g extract DW). The pigment composition of Picochlorum sp. SBL2 extract is similar to that reported in a previous work [54], except for the presence of canthaxanthin. In fact, the strain of Picochlorum sp. studied by de la Vega and co-workers [54] was suggested by the authors as a promising feedstock for the exploitation of carotenoids and biodiesel production. Both Nannochloris strains had similar carotenoid composition. However, Nannochloris sp. SBL1 had a higher concentration of carotenoids than those detected in SBL4. Except for zeaxanthin, the identified pigments in Nannochloris strains were previously observed in Nannochloris atomus [55]. To the authors' knowledge, the pigment composition of Desmochloris has never been reported previously. Regarding the total amount of carotenoids, Picochlorum sp. had the highest amounts (3.55 mg/g extract DW), followed by Nannochloris SBL1 (3.07 mg/g extract DW) and Desmochloris SBL3 (1.74 mg/g extract DW), whereas Nannochloris sp. SBL4 had the lowest content (1.62 mg/g extract DW).

Table 2. HPLC analysis of phenolic and carotenoid compounds ( $\mathrm{mg} / \mathrm{g}$ extract DW) of methanol extracts of four strains belonging to the Nannochloris (SBL1 and SBL4), Picochlorum (SBL2) and Desmochloris (SBL3) genera.

\begin{tabular}{lcccc}
\hline Compound & SBL1 & SBL2 & SBL3 & SBL4 \\
\hline Gallic acid & 0.06 & 0.11 & nd & nd \\
Coumaric acid & 0.06 & 0.35 & 0.07 & 0.07 \\
Salicylic acid & nd & 0.64 & nd & 0.14 \\
Total phenolics & $\mathbf{0 . 1 2}$ & $\mathbf{1 . 1}$ & $\mathbf{0 . 0 7}$ & $\mathbf{0 . 2 1}$ \\
Neoxanthin & 0.02 & 1.45 & 0.11 & 0.06 \\
Violaxanthin & 0.16 & 0.44 & 0.05 & 0.15 \\
Lutein & 1.29 & 0.89 & 0.60 & 0.19 \\
Zeaxanthin & 0.51 & 0.54 & 0.48 & 0.10 \\
Canthaxanthin & nd & 1.15 & nd & nd \\
B-carotene & 1.08 & 0.52 & 0.61 & 1.19 \\
Total carotenoids & $\mathbf{3 . 0 7}$ & $\mathbf{3 . 5 5}$ & $\mathbf{1 . 7 4}$ & $\mathbf{1 . 6 2}$ \\
\hline
\end{tabular}

nd, not detected.

Although a direct relationship could not be established between either the phenolics or pigment composition and the RSA observed for the extracts, synergistic effects between different pigments are known to increase the RSA towards the DPPH radical [56]. In addition, interactions with or between phenolic compounds cannot be ruled out. Nonetheless, our results reveal that all strains of microalgae tested can be exploited as feedstocks for the production of carotenoids with high commercial value for different applications. There is increasing market demand for carotenoids with an estimated annual growth rate of $2.3 \%$ and a global market that can reach $\$ 1.4$ billion by 2018 [57]. Carotenoids, such as lutein, have a wide applicability in nutritional and pharmaceutical/biomedical industries, because of their antioxidant and anti-carcinogenic properties [31], prevention of cognitive impairment [58], eye supplements formulation [54] and food and feed additives for the pigmentation industry [53].

These commercially-relevant metabolites (e.g., carotenoids and phenolics) can be key to the development and sustainability of a future microalgae-based biorefinery venture, coupling the exploitation 
of lipids for biodiesel and/or edible oils purposes with the co-production of fine and/or bulk chemicals with high commercial value for other biotechnological applications [59]. For example, carotenoid-containing streams coming from biomass down-processing, but unused for biodiesel production, could upgrade the total value of the feedstock and enable the future deployment of biorefineries for growing and processing microalgal strains already adapted to the conditions found in the Red Sea. Although these strains contain high-added value compounds, for the setup of a biorefinery, an effective downstream procedure enabling the separation of the oil/lipids from these streams, in laboratory and industrial settings, needs to be developed. Moreover, the development of a microalgae biorefinery must take into account the market size for these high-added value compounds. When lipids are used for the production of biofuels, the co-production of high value metabolites may saturate the market currently available for these niche products [60]. To overcome market-size limitations, extracted lipids found in the biomass can be diverted to applications other than biofuel production, including nutritional (food and feed), pharmaceutical and cosmetic industries. Alternatively, if biofuels must be produced for strategic reasons concerning fuel security, the generated co-products may be diversified, and novel emerging markets can be explored [60-62]. Some examples of possible emerging markets are active food packaging and organic aquaculture feed, which present increasing demands for components containing antioxidants, stabilizers and coloring agents from biological sources [63,64].

\section{Experimental Section}

\subsection{Chemicals}

All chemicals used in the experiments were of analytical grade. AChE (EC.3.1.1.7) from electric eel, BuChE (EC.232.579.2) from equine serum, acetylthiocholine iodide (ATChI), butyrylthiocholine iodide (BTChI), 5,5-dithiobis-(2-nitrobenzoic acid (DTNB), galantamine, gallic acid, Tween 40, pyrocatechol violet, DPPH and all commercial standards for HPLC were purchased from Sigma (Steinheim, Germany). Ethylenediamine tetraacetic acid (EDTA) and sodium carbonate $\left(\mathrm{Na}_{2} \mathrm{CO}_{3}\right)$ were acquired from Fluka (Steinheim, Germany). Merck (Darmstadt, Germany) supplied ferrozine, copper sulfate pentahydrate and Folin-Ciocalteu (F-C), while methanol was obtained from Fischer Scientific (Loughborough, UK). Additional reagents and solvents were purchased from VWR International (Leuven, Belgium).

\subsection{Microalgae Culture}

Microalgae strains, namely Nannochloris sp. SBL1, Picochlorum sp. SBL2, Desmochloris sp. SBL3 and Nannochloris sp. SBL4 were previously isolated by Pereira et al. [9]. Biomass was cultured in agar plates (1.5\% agar) and further grown on liquid medium in $80-\mathrm{mL}$ test tubes using Guillard's $\mathrm{F} / 2$ medium and enriched seawater, as described in Pereira et al. [65]. Cultures were grown for 12 days at $23{ }^{\circ} \mathrm{C}$, at a photon flux density of $100 \mu \mathrm{mol} \cdot \mathrm{m}^{-2} \cdot \mathrm{s}^{-1}$ with a $24-\mathrm{h}$ light photoperiod. Upon culturing, biomass was harvested by centrifugation $(5000 \times \mathrm{g}, 5 \mathrm{~min})$ and freeze-dried until the extraction procedure. 


\subsection{Extraction}

Dried microalgae biomass was mixed with methanol $(1: 40, w / v)$ and the cells disrupted using an IKA T10B Ultra-Turrax disperser for $2 \mathrm{~min}$, on ice. Extractions were performed overnight at room temperature (RT, $20{ }^{\circ} \mathrm{C}$ ) under continuous stirring. The supernatants were recovered from extracted biomass by centrifugation $(10,000 \times \mathrm{g}, 10 \mathrm{~min})$, filtered (Whatman No. 4 filter) and dried on a rotary evaporator $\left(45^{\circ} \mathrm{C}\right)$ under vacuum. Dried extracts were resuspended in methanol to a final concentration of $20 \mathrm{mg} / \mathrm{mL}$ and stored at $-20^{\circ} \mathrm{C}$.

\subsection{Antioxidant Activity}

\subsubsection{RSA on DPPH Radical}

RSA on the DPPH free radical was evaluated according to the method of Brand-Williams adapted to a 96-well microplate scale [66]. The absorbance was measured at $515 \mathrm{~nm}$ in a microplate reader, and the RSA was expressed as percent inhibition, relative to a negative control, containing methanol in place of the sample. Butylated hydroxytoluene $(\mathrm{BHT}, 1 \mathrm{mg} / \mathrm{mL})$ was used as a positive control.

\subsubsection{Metal Chelating Activity on Iron and Copper Ions}

Iron chelating activity was determined by measuring the formation of the $\mathrm{Fe}^{2+}$-ferrozine complex according to Megías et al. [67], with some modifications. The change in color was measured in a microplate reader at $562 \mathrm{~nm}$. Copper chelating activity was determined using pyrocatechol violet (PV), as described by Megías et al. [67]. The change in color of the solution was measured at $632 \mathrm{~nm}$. The synthetic metal chelator EDTA was used as a positive control at the concentration of $1 \mathrm{mg} / \mathrm{mL}$ for both metals.

\subsection{AChE and BuChE Inhibitory Activity}

$\mathrm{AChE}$ and BuChE inhibitory activities were measured by the Ellman method [68] as described by Orhan et al. [69]. Briefly, $20 \mu \mathrm{L}$ of each extract (1 and $10 \mathrm{mg} / \mathrm{mL}$ ) were mixed with $140 \mu \mathrm{L}$ of $0.1 \mathrm{mM}$ sodium phosphate buffer (pH 8.0) and $20 \mu \mathrm{L}$ of AChE or BuChE solution $(0.28 \mathrm{U} / \mathrm{mL}$ ) in 96-well microplates and incubated at RT for $15 \mathrm{~min}$. The reaction was initiated by adding $10 \mu \mathrm{L}$ of ATChI or BTChI $(4 \mathrm{mg} / \mathrm{mL})$ together with $20 \mu \mathrm{L}$ of DTNB $(1.2 \mathrm{mg} / \mathrm{mL})$. The hydrolysis of ATChI or BTChI was monitored by the formation of the yellow 5-thio-2-nitrobenzoate anion as a result of the reaction of DTNB with thiocholines catalyzed by the enzyme, at $412 \mathrm{~nm}$, using a microplate reader. Results were expressed as $\mathrm{AChE}$ and $\mathrm{BuChE}$ percentage inhibition relative to a negative control, containing methanol in place of the sample. Galantamine was used as the positive control $(1 \mathrm{mg} / \mathrm{mL})$.

\subsection{TYRO Inhibitory Activity}

The inhibitory activity against TYRO was determined by the method reported by Nerya et al. [70] with modifications, using L-tyrosine as the substrate. Samples $(70 \mu \mathrm{L}$ at the concentrations of 1, 5 and $10 \mathrm{mg} / \mathrm{mL}$ ) were mixed in 96-well microplates with $30 \mu \mathrm{L}$ of TYRO (333 Units/mL in phosphate buffer, $\mathrm{pH}$ 6.5) and incubated for $5 \mathrm{~min}$. Then, $110 \mu \mathrm{L}$ of substrate (L-tyrosine, $2 \mathrm{mM}$ in water) were 
added to each well and further incubated for $30 \mathrm{~min}$ at RT. The optical densities of the wells were read at $492 \mathrm{~nm}$. Results were expressed as TYRO percentage inhibition relative to a negative control, containing methanol in place of the sample. Arbutin was used as the positive control at the concentration of $1 \mathrm{mg} / \mathrm{mL}$.

\subsection{In Vitro Cytotoxic Activity}

HepG2, HeLa and S17 cells were kindly provided by the Centre for Biomedical Research (CBMR), University of Algarve. The HepG2 cell line was maintained in RPMI-1640 culture media supplemented with glucose $(1000 \mathrm{mg} / \mathrm{mL}), 10 \%$ heat-inactivated fetal bovine serum (FBS), L-glutamine (2 $\mathrm{mM})$, penicillin $(50 \mathrm{U} / \mathrm{mL})$ and streptomycin $(50 \mu \mathrm{g} / \mathrm{mL})$. S17 and HeLa cells were grown in DMEM culture media supplemented with glucose $(1000 \mathrm{mg} / \mathrm{mL}), 10 \%$ FBS, L-glutamine $(2 \mathrm{mM})$, penicillin $(50 \mathrm{U} / \mathrm{mL})$ and streptomycin $(50 \mu \mathrm{g} / \mathrm{mL})$. Both lines were grown at $37{ }^{\circ} \mathrm{C}$ and $5.0 \% \mathrm{CO}_{2}$ in a humidified atmosphere.

Exponentially-growing cells were seeded at a density of $5 \times 10^{3}$ cells/well on 96-well plates and incubated for $24 \mathrm{~h}$ at $37{ }^{\circ} \mathrm{C}$ in $5.0 \% \mathrm{CO}_{2}$. Then, the extracts $(100 \mu \mathrm{L})$ were applied at a concentration of $125 \mu \mathrm{g} \mathrm{mL}$ for $72 \mathrm{~h}$. Positive control cells were treated with etoposide at the same concentration and incubation period as the extracts, while negative control cells were treated with DMSO at the highest concentration used in test wells $(0.5 \%, v / v)$. The MTT assay [30] was used to assess the effect of the extracts on mitochondrial metabolic activity, as an indicator of cell viability. Results were expressed in terms of cell viability (\%).

\subsection{In Vitro Antileishmanial Activity}

Promastigote forms of $L$. infantum (MHOM/PT/88/IMT-151) were provided by the Medical Parasitology Unit of the Institute of Hygiene and Tropical Medicine (New University of Lisbon, Portugal) and maintained in RPMI-1640 medium supplemented with 10\% heat-inactivated FBS, L-glutamine $(2 \mathrm{mM})$, penicillin $(50 \mathrm{U} / \mathrm{L})$ and streptomycin $(0.05 \mathrm{mg} / \mathrm{L})$, at $24{ }^{\circ} \mathrm{C}$ in tissue flasks. For the determination of the antileishmanial activity, L. infantum promastigotes $\left(1 \times 10^{7}\right.$ parasites $\left./ \mathrm{mL}\right)$ were incubated in 96-well plates with the extracts at the concentration of $250 \mu \mathrm{g} / \mathrm{mL}$, for $48 \mathrm{~h}$. Positive control parasites were treated with amphotericin B at a concentration of $0.23 \mu \mathrm{g} / \mathrm{mL}$ and during the same incubation period as the extracts, while negative control cells were treated with DMSO at the highest concentration used in test wells $(0.5 \% \mathrm{v} / v)$. The MTT assay [30] was used to assess the effect of the extracts on parasites viability. After incubation, $20 \mu \mathrm{L}$ of MTT $(5 \mathrm{mg} / \mathrm{mL}$ in PBS $)$ were added to each well, and plates were re-incubated for $2 \mathrm{~h}$, at $37^{\circ} \mathrm{C}$. Then, plates were centrifuged $\left(15 \mathrm{~min}, 4^{\circ} \mathrm{C}\right.$, $1479 \times g$ ), the supernatants discarded and $150 \mu \mathrm{L}$ of DMSO added to each well in order to dissolve the formazan crystals. Absorbance was measured at $590 \mathrm{~nm}$, and results were expressed in terms of cell viability $(\%)$.

\section{9. $T P C$}

The TPC of the extracts was determined by the F-C assay according to Velioglu et al. [71]. The extracts $(5 \mu \mathrm{L}$ at the concentration of $10 \mathrm{mg} / \mathrm{mL})$ were mixed with 10 -fold diluted $\mathrm{F}-\mathrm{C}$ reagent in distilled water $(100 \mu \mathrm{L})$ and incubated at RT for $5 \mathrm{~min}$. Then, $100 \mu \mathrm{L}$ of sodium carbonate $\left(\mathrm{Na}_{2} \mathrm{CO}_{3}\right.$, 
$75 \mathrm{~g} / \mathrm{L}, w / v$ ) were added; samples were incubated for $90 \mathrm{~min}$ at RT, and the absorbance was measured at $725 \mathrm{~nm}$, on a microplate reader. Results were expressed as GAE using a calibration curve of gallic acid standard solutions, in milligrams per gram of extract (mg GAE/g DW).

\subsection{HPLC Analysis}

\subsubsection{Analysis of Phenolic Compounds}

The extracts at the concentration of $10 \mathrm{mg} / \mathrm{mL}$ in ultrapure water were analyzed by HPLC-DAD (Agilent 1100 Series LC system, Boeblingen, Germany) formed by the following modules: vacuum degasser (G1322A), quaternary pump (G1311A), autosampler (G1313A), thermostated column compartment (G1316A) and a diode array detector (G1315B). Data acquisition and instrumental control were performed by the software LC3D ChemStation (Version Rev.A.10.02(1757), Agilent Technologies, Boeblingen, Germany). Analyses were performed on a Mediterranea Sea18 column, $15 \times 0.21 \mathrm{~cm}, 5-\mu \mathrm{m}$ particle size (Teknokroma, Barcelona, Spain). The mobile phase consisted of a mixture of methanol (Solvent $\mathrm{A}$ ) and $2.5 \%$ acetic acid aqueous solution with the following gradient: 0-5 min: 10\% A, 5-10 min: 10\%-30\% A, 10-40 min: 30\%-90\% A, 40-45 min: 90\% A, 45-55 min: 90\%-10\% A and 55-60 min: 10\% A, using a flow of $0.5 \mathrm{~mL} / \mathrm{min}$. The injection volume was $20 \mu \mathrm{L}$ with a draw speed of $200 \mu \mathrm{L} / \mathrm{min}$. The detector was set at 210, 280 (used for quantification), 320 and $350 \mathrm{~nm}$. For chemical identification, the retention parameters of each assay were compared with the standard controls and the peak purity with the UV-visible spectral reference data. The levels of the different compounds were extrapolated from calibration standard curves. Commercial standards (gallic acid, p-hydroxybenzoic acid, catechin, vanillic acid, caffeic acid, syringic acid, epigallocatechin gallate, coumaric acid, salicylic acid, ferulic acid, rosmarinic acid, 4-hydroxybenzaldehyde, apigenin, BHT, chlorogenic acid, epicatechin, epigallocatechin, flavone, gentisic acid, m-hydroxybenzoic acid, oleanolic acid, quercetin, resveratrol, rutin hydrate, trans-cinnamic acid and uvaol) were prepared in methanol $(10,000 \mathrm{mg} / \mathrm{L})$ and diluted with ultrapure water in the desired concentration.

\subsubsection{Analysis of Pigment Composition}

All methanolic extracts were injected at the concentration of $10 \mathrm{mg} / \mathrm{mL}$ with an injection volume of $20 \mu \mathrm{L}$. Carotenoids were analyzed with a Knauer smartline 5000 HPLC equipped with a Knauer Smartline pump 1000 and Knauer UV detector 2600. The HPLC was performed using Luna 5u C18 100A $(5 \mu \mathrm{m}, 250 \times 4.6 \mathrm{~mm})$. The mobile phase consisted of acetonitrile $(\mathrm{ACN})$ and ethyl acetate (EA) with the following gradient: 0-15 min: 100\% ACN, 15-35 min: 50\%-50\% ACN, 35-45 min: $100 \% \mathrm{ACN}$, using a flow of $1 \mathrm{~mL} / \mathrm{min}$. The identification of compounds was achieved by comparing the retention time and the UV spectra with those of pure commercial standards. Quantification was performed using calibration curves prepared for each of the pigments analyzed (fucoxanthin, lutein, violaxanthin, neoxanthin zeaxanthin astaxanthin, canthaxanthin, chlorophyll $a$, lycopene and $\beta$-carotene).

\subsection{Statistical Analysis}

Results were expressed as the mean \pm standard deviation, and experiments were conducted at least in triplicate. Significant differences were assessed by analysis of variance (ANOVA) or the Duncan's 
new multiple range test when the parametricity of data did not prevail. SPSS statistical package for Windows (Release 15.0, SPSS Inc., Chicago, IL, USA) was used.

\section{Conclusions}

Our results indicate that biomass from the microalgae Nannochloris sp., Picochlorum sp. and Desmochloris sp. isolated from the Red Sea not only have fatty acid methyl ester profiles considered as ideal for biodiesel production [9], but also contain molecules with relevant bioactivities, including antioxidant, inhibition of BuChE and TYRO, cytotoxic and antileishmanial activities. Moreover, chemical characterization of the extracts of all strains revealed the presence of different phenolic and carotenoid compounds, some of which have high market value. Taken as a whole, these results suggest that the biomass of these microalgae is promising as feedstocks for supplying high-value compounds to the biomedical/pharmaceutical and food/feed industries. Future research will focus on the development of a suitable downstream procedure for the coupled extraction of lipids and target co-products studied in the present report.

\section{Acknowledgments}

This work was supported by the National Science, Technology and Innovation Program of King Abdulaziz Medical City for Science and Technology, Project No. NPST, 11-ENE 1719-02, Riyadh, Saudi Arabia. Carolina Bruno de Sousa was supported by the Foundation for Science and Technology (FCT), Portugal (SFRH/BD/78062/2011) doctoral grant. Luísa Custódio was supported by the FCT Investigator Programme (IF/00049/2012). Nuno da Rosa Neng thanks FCT for the post-doc grant (SFRH/BPD/86071/2012) and funding (Pest-OE/QUI/UI0612/2013). We would like to acknowledge Monya Costa and João Silva (Algae Research Group, Centre of Marine Sciences) for kindly providing the standards of neoxanthin and violaxanthin.

\section{Author Contributions}

The experimental design was carried out by Hugo Pereira, Luísa Custódio, Khalid M. Abu-Salah, Salman A. Alrokayan, Fouzi Mouffouk, Radhouan Ben-Hamadou, Luísa Barreira and João Varela. The laboratory experiments were performed by Hugo Pereira, Luísa Custódio, Maria João Rodrigues, Khalid M. Abu-Salah, Salman A. Alrokayan, Marta Oliveira, Carolina Bruno de Sousa (bioactivity assays) and Nuno R. Neng and José M. Nogueira (chemical characterization). The manuscript was written by Hugo Pereira, Luísa Custódio, Luísa Barreira, Carolina Bruno de Sousa, Khalid M. Abu-Salah, Radhouan Ben-Hamadou and João Varela.

\section{Conflicts of Interest}

The authors declare no conflict of interest.

\section{References}

1. Richmond, A. Handbook of Microalgal Culture: Biotechnology and Applied Phycology; Blackwell Science: Ames, IA, USA, 2004. 
2. Coesel, S.N.; Baumgartner, A.C.; Teles, L.M.; Ramos, A.R.; Henriques, N.M.; Cancela, L.; Varela, J. Nutrient limitation is the main regulatory factor for carotenoid accumulation and for Psy and Pds steady state transcript levels in Dunaliella salina (Chlorophyta) exposed to high light and salt stress. Mar. Biotechnol. 2008, 10, 601-611.

3. Borowitzka, M.A. High-value products from microalgae-their development and commercialisation. J. Appl. Phycol. 2013, 25, 743-756.

4. Sánchez, J.F.; Fernández, J.M.; Acién, F.G.; Rueda, A.; Pérez-Parra, J.; Molina, E. Influence of culture conditions on the productivity and lutein content of the new strain Scenedesmus almeriensis. Process. Biochem. 2008, 43, 398-405.

5. Pulz, O.; Gross, W. Valuable products from biotechnology of microalgae. Appl. Microbiol. Biotechnol. 2004, 65, 635-648.

6. Patil, V.; Tran, K.-Q.; Ragnar, H.; Giselrød, H.R. Towards sustainable production of biofuels from microalgae. Int. J. Mol. Sci. 2008, 9, 1188-1195.

7. Stephens, E.; Ross, I.L.; King, Z.; Mussgnug, J.H.; Kruse, O.; Posten, C.; Borowitzka, M.A.; Hankamer, B. An economic and technical evaluation of microalgal biofuels. Nat. Biotechnol. 2010, 28, 126-128.

8. Wijffels, R.H.; Barbosa, M.J. An outlook on microalgal biofuels. Science 2010, 329, 796-799.

9. Pereira, H.; Barreira, L.; Custódio, L.; Alrokayan, S.; Mouffouk, F.; Varela, J.; Abu-Salah, K.M.; Ben-Hamadou, R. Isolation and fatty acid profile of selected microalgae strains from the Red Sea for biofuel production. Energies 2013, 6, 2773-2783.

10. Valko, M.; Leibfritz, D.; Moncol, J.; Cronin, M.T.D.; Mazur, M.; Telser, J. Free radicals and antioxidants in normal physiological functions and human disease. Int. J. Biochem. Cell Biol. 2007, 39, 44-84.

11. Guerin, M.; Huntley, M.E.; Olaizola, M. Haematococcus astaxanthin: Applications for human health and nutrition. Trends Biotechnol. 2003, 21, 210-216.

12. Abe, K.; Hattor, H.; Hiran, M. Accumulation and antioxidant activity of secondary carotenoids in the aerial microalga Coelastrella striolata var. multistriata. Food Chem. 2005, 100, 656-661.

13. Konishi, T. Brain oxidative stress as basic target of antioxidant traditional oriental medicines. Neurochem. Res. 2009, 34, 711-716.

14. Wang, H.M.; Pan, J.L.; Chen, C.Y.; Chiu, C.C.; Yang, M.H.; Chang, H.W.; Chang, J.S. Identification of anti-lung cancer extract from Chlorella vulgaris $\mathrm{C}-\mathrm{C}$ by antioxidant property using supercritical carbon dioxide extraction. Process Biochem. 2010, 45, 1865-1872.

15. Weinreb, O.; Mandel, S.; Bar-Am, O.; Amit, T. Iron-chelating backbone coupled with monoamine oxidase inhibitory moiety as novel pluripotential therapeutic agents for Alzheimer's disease: A tribute to Moussa Youdim. J. Neural Transm. 2011, 118, 479-492.

16. Uttara, B.; Ajay, S.V.; Zamboni, P.; Mahajan, R.T. Oxidative stress and neurodegenerative diseases: A review of upstream and downstream antioxidant therapeutic options. Curr. Neuropharmacol. 2009, 7, 65-74.

17. Custódio, L.; Justo, T.; Silvestre, L.; Barradas, A.; Vizetto, C.; Pereira, H.; Barreira, L.; Rauter, A.P.; Alberício, F.; Varela, J. Microalgae of different phyla display antioxidant, metal chelating and acetylcholinesterase inhibitory activities. Food Chem. 2012, 131, 134-140. 
18. Gaeta, A.; Hider, R.C. The crucial role of metal ions in neurodegeneration: The basis for a promising therapeutic strategy. Br. J. Pharmacol. 2005, 146, 1041-1059.

19. Poggiali, E.; Cassinerio, E.; Zanaboni, L.; Cappellini, M.D. An update on iron chelation therapy. Blood Transfus. 2012, 10, 411-422.

20. Robert, A.; Liu, Y.; Nguyen, M.; Meunier, B. Regulation of copper and iron homeostasis by metal chelators: A possible chemotherapy for Alzheimer's disease. Acc. Chem. Res. 2015, 48, 1332-1339.

21. Filho, J.; Medeiros, K.; Diniz, M.; Batista, L.; Athayde-Filho, P.; Silva, M.; da Cunha, E. Natural products inhibitors of the enzyme acetylcholinesterase. Braz. J. Pharmacogn. 2006, 16, 258-285.

22. Vinutha, B.; Prashanth, D.; Salma, K.; Sreeja, S.L.; Pratiti D.; Padmaja, R.; Radhika, S.; Amit A.; Venkateshwarlu, K.; Deepak M. Screening of selected Indian medicinal plants for acetylcholinesterase inhibitory activity. J. Ethnopharmacol. 2007, 109, 359-363.

23. Custódio, L.; Soares, F.; Pereira, H.; Rodrigues, M.J.; Barreira, L.; Rauter, A.P.; Alberício, F.; Varela, J. Botryococcus braunii and Nannochloropsis oculata extracts inhibit cholinesterases and protect human dopaminergic SH-SY5Y cells from $\mathrm{H}_{2} \mathrm{O}_{2}$-induced cytotoxicity. J. Appl. Phycol. 2015, 25, 839-848.

24. Greig, N.H.; Utsuki, T.; Ingram, D.K.; Wang, Y.; Pepeu, G.; Scali, C.; Yu, Q.-S.; Mamczarz, J.; Holloway, H.W.; Giordano, T.; et al. Selective butyrylcholinesterase inhibition elevates brain acetylcholine, augments learning and lowers Alzheimer $\beta$-amyloid peptide in rodent. Proc. Natl. Acad. Sci. USA 2005, 102, 17213-17218.

25. Graybiel, A.; Ragsdale, C.W., Jr. Pseudocholinesterase staining in the primary visual pathway of the macaque monkey. Nature 1982, 299, 439-442.

26. Bartorelli, L.; Giraldi, C.; Saccardo, M.; Cammarata, S.; Bottini, G.; Fasanaro, A.M.; Trequattrini, A. Effects of switching from an AChE inhibitor to a dual AChE-BuChE inhibitor in patients with Alzheimer's disease. Curr. Med. Res. Opin. 2005, 21, 1809-1817.

27. Giacobini, E.; Spiegel, R.; Enz, A.; Veroff, A.; Cutler, N. Inhibition of acetyl- and butyryl-cholinesterase in the cerebrospinal fluid of patients with Alzheimer's disease by rivastigmine: Correlation with cognitive benefit. J. Neural Trans. 2002, 109, 1053-1065.

28. Chiou, S.-Y.; Weng, T.-T.; Lin, G.-Z.; Lu, R.-J.; Jian, S.-Y.; Lin, G. Molecular docking of different inhibitors and activators to butyrylcholinesterase. J. Biomol. Struct. Dyn. 2015, 33, 563-572.

29. Khan, M.T.H. Molecular design of tyrosinase inhibitors: A critical review of promising novel inhibitors from synthetic origins. Pure Appl. Chem. 2007, 79, 2277-2295.

30. Mosmann, T. Rapid colorimetric assay for cellular growth and survival: Application to proliferation and cytotoxicity assays. J. Immunol. Methods 1983, 65, 55-63.

31. Guedes, A.C.; Amaro, H.M.; Malcata, F.X. Microalgae as sources of high added-value compounds-A brief review of recent work. Biotechnol. Prog. 2011, 27, 597-613.

32. Plaza, M.; Herrero, M.; Cifuentes, A.; Ibáñez, E. Innovative natural functional ingredients from microalgae. J. Agric. Food Chem. 2009, 57, 7159-7170. 
33. Custódio, L.; Soares, F.; Pereira, H.; Barreira, L.; Vizetto-Duarte, C.; Rodrigues, M.J.; Rauter, A.P.; Alberício, F.; Varela, J. Fatty acid composition and biological activities of Isochrysis galbana T-ISO, Tetraselmis sp. and Scenedesmus sp.: Possible application in the pharmaceutical and functional food industries. J. Appl. Phycol. 2014, 26, 151-161.

34. Campino, L.; Pratlong, F.; Abranches, P.; Rioux, J.-A.; Santos-Gomes, G.; Alves-Pires, C.; Cortes, S.; Ramada, J.; Cristovão, J.M.; Afonso, M.O.; et al. Leishmaniasis in Portugal: Enzymatic Polymorphism of Leishmania infantum based on Identification of 213 Strains. Trop. Med. Int. Health 2006, 11, 1708-1714.

35. Control of the Leishmaniases: Report of a Meeting of the WHO Expert Committee on the Control of Leishmaniases, Geneva, 22-26 March 2010, WHO Technical Report Series 949; World Health Organization: Geneva, Switzerland, 2010; p. 186.

36. Garrote, J.I.; Gutierrez, M.P.; Lopez Izquierdo, R.; Duenas, M.A.I.; Zarzosa, P.; Canavete, C.; El Bali, M.; Almaraz, A.; Miguel, A.; Bratos, A.; et al. Seroepidemiologic study of Leishmania infantum infection in Castilla-Leon, Spain. Am. J. Trop. Med. Hyg. 2004, 71, 403-406.

37. Campino, L.; Maia, C. Epidemiologia das leishmanioses em Portugal. Acta Med. Port. 2010, 23, 859-864.

38. Croft, S.L.; Sundar, S.; Fairlamb, A.H. Drug Resistance in Leishmaniasis. Clin. Microbiol. Rev. 2006, 19, 111-126.

39. Tempone, A.G.; Martins de Oliveira, C.; Berlinck, R.G. Current approaches to discover marine antileishmanial natural products. Planta Med. 2011, 77, 572-585.

40. Hotez, P.J.; Pecoul, B. "Manifesto" for advancing the control and elimination of neglected tropical diseases. PLoS Negl. Trop. Dis. 2010, 4, e718.

41. Maia, C.; Nunes, M.; Cristóvão, J.; Campino, L. Experimental canine leishmaniasis: Clinical, parasitological and serological follow-up. Acta Trop. 2010, 116, 193-199.

42. Watts, K.R.; Tenney, K.; Crews, P. The structural diversity and promise of antiparasitic marine invertebrate-derived small molecules. Curr. Opin. Biotechnol. 2010, 21, 808-818.

43. Franco, D.; Sineiro, J.; Rubilar, M.; Sánchez, M.; Jerez, M.; Pinelo, M.; Costoya, N.; Núñez, M.J. Polyphenols from plant materials: Extraction and antioxidant power. Electron J. Environ. Agric. Food Chem. 2008, 7, 3210-3216.

44. Khoddami, A.; Wilkes, M.A.; Roberts, T.H. Techniques for analysis of plant phenolic compounds. Molecules 2013, 18, 2328-2375.

45. Duval, B.; Shetty, K.; Thomas, W.H. Phenolic compounds and antioxidant properties in the snow alga Chlamydomonas nivalis after exposure to UV light. J. Appl. Phycol. 2000, 11, 559-566.

46. Goiris, K.; Muylaert, K.; Voorspoels, S.; Noten, B.; De Paepe, D.; Baart, G.J.E.; de Cooman, L. Detection of flavonoids in microalgae from different evolutionary lineages. J. Phycol. 2014, 50, 483-492.

47. Ignat, I.; Volf, I.; Popa, V.I. A critical review of methods for characterisation of polyphenolic compounds in fruits and vegetables. Food Chem. 2011, 126, 1821-1835.

48. Naczk, M.; Shahidi, F. Extraction and analysis of phenolics in food. J. Chromatogr. A 2004, 1054, 95-111.

49. Soobrattee, M.A.; Neergheen, V.S.; Luximon-Ramma, A.; Aruoma, O.I.; Bahorun, T. Phenolics as potential antioxidant therapeutic agents: Mechanism and actions. Mutat. Res. 2005, 579, 200-213. 
50. Cai, Y.; Luo, Q.; Sun, M.; Corke, H. Antioxidant activity and phenolic compounds of 112 traditional Chinese medicinal plants associated with anticancer. Life Sci. 2004, 74, 2157-2184.

51. Spolaore, P.; Joannis-Cassan, C.; Duran, E.; Isambert, A. Commercial applications of microalgae. J. Biosci. Bioeng. 2006, 101, 87-96.

52. Goiris, K.; Muylaert, K.; Fraeye, I.; Foubert, I.; de Brabanter, J.; de Cooman, L. Antioxidant potential of microalgae in relation to their phenolic and carotenoid content. J. Appl. Phycol. 2012, 24, 1477-1486.

53. Guedes, A.C.; Amaro, H.M.; Malcata, F.X. Microalgae as sources of carotenoids. Mar. Drugs 2011, 9, 625-644.

54. De la Vega, M.; Díaz, E.; Vila, M.; León, R. Isolation of a new strain of Picochlorum sp. and characterization of its potential biotechnological applications. Biotechnol. Prog. 2011, 27, $1535-1543$.

55. Jeffrey, S.W. Paper-chromatographic separation of chlorophylls and carotenoids from marine algae. Biochem. J. 1961, 80, 336-342.

56. Liu, D.; Shi, J.; Ibarra, A.C.; Kakuda, Y.; Xue, S.J. The scavenging capacity and synergistic effects of lycopene, vitamin $\mathrm{E}$, vitamin $\mathrm{C}$, and $\beta$-carotene mixtures on the DPPH free radical. Lebensm. Wiss. Technol. 2006, 41, 1344-1349.

57. Zhang, J.; Sun, Z.; Sun, P.; Chen, T.; Chen, F. Microalgal carotenoids: Beneficial effects and potential in human health. Food Funct. 2014, 5, 413-425.

58. Nakashima, Y.; Ohsawa, I.; Konishi, F.; Hasegawa, T.; Kumamoto, S.; Suzuki, Y.; Ohta, S. Preventive effects of Chlorella on cognitive decline in age-dependent dementia model mice. Neur. Lett. 2009, 464, 193-198.

59. Vanthoor-Koopmans, M.; Wijffels, R.H.; Barbosa, M.J.; Eppink, M.H. Biorefinery of microalgae for food and fuel. Bioresour. Technol. 2013, 135, 142-149.

60. Zhu, L. Biorefinery as a promising approach to promote microalgae industry: An innovative framework. Renew. Sustain. Energy Rev. 2015, 41, 1376-1384.

61. Wijffels, R.H.; Barbosa, M.J.; Eppink, M.H.M. Microalgae for the production of bulk chemicals and biofuels. Biofuels Bioprod. Bioref. 2010, 4, 287-295.

62. Subhadra, B.G.; Edwards, M. Coproduct market analysis and water footprint of simulated commercial algal biorefineries. Appl. Energy 2011, 88, 3515-3523.

63. Restuccia, D.; Spizzirri, U.G.; Parisi, O.I.; Cirillo, G.; Curcio, M.; Iemma, F.; Puoci, F.; Vinci, G.; Picci, N. New EU regulation aspects and global market of active and intelligent packaging for food industry applications. Food Control 2010, 21, 1425-1435.

64. Mente, E.; Karalazos, V.; Karapanagiotidis, I.T.; Pita, C. Nutrition in organic aquaculture: An inquiry and a discourse. Aquac. Nutr. 2011, 17, 798-817.

65. Pereira, H.; Barreira, L.; Mozes, A.; Florindo, C.; Polo, C.; Duarte, C.V.; Custódio, L.; Varela, J. Microplate-based high throughput screening procedure for the isolation of lipid-rich marine microalgae. Biotechnol. Biofuels 2011, 4, 61.

66. Moreno, S.; Scheyer, T.; Romano, C.; Vojnov, A. Antioxidant and antimicrobial activities of rosemary extracts linked to their polyphenol composition. Free Radic. Res. 2006, 40, 223-231. 
67. Megías, C.; Pastor-Cavada, E.; Torres-Fuentes, C.; Girón-Calle, J.; Alaiz, M.; Jua, R.; Julio, P.; Javier, V. Chelating, antioxidant and antiproliferative activity of Vicia sativa polyphenol extracts. Eur. Food Res. Technol. 2009, 230, 353-359.

68. Ellman, G.L.; Courtney, K.D.; Andres, V.; Featherstone, R.M. A new and rapid colorimetric determination of acetylcholinesterase activity. Biochem. Pharmacol. 1961, 7, 88-95.

69. Orhan, I.; Kartal, M.; Naz, Q.; Ejaz, A.; Yilmaz, G.; Kan, Y.K.B.; Sener, B.; Choudhary, M.I. Antioxidant and anticholinesterase evaluation of selected Turkish Salvia species. Food Chem. 2007, 103, 1247-1254.

70. Nerya, O.; Vaya, J.; Musa, R.; Izrael, S.; Ben-Arie, R.; Tamir, S. Glabrene and isoliquiritigenin as tyrosinase inhibitors from licorice roots. J. Agric. Food Chem. 2003, 51, 1201-1207.

71. Velioglu, Y.S.; Mazza, G.; Gao, L.; Oomah, B.D. Antioxidant activity and total phenolics in selected fruits, vegetables, and grain products. J. Agric. Food Chem. 1998, 46, 4113-4117.

(C) 2015 by the authors; licensee MDPI, Basel, Switzerland. This article is an open access article distributed under the terms and conditions of the Creative Commons Attribution license (http://creativecommons.org/licenses/by/4.0/). 